\title{
Measuring agency in children: The development and validation of the War Child Agency Assessment Scale - Palestinian version (WCAAS-Pal)
}

\author{
Guido Veronese $^{1}$ D $\cdot$ Alessandro Pepe ${ }^{1} \cdot$ Federica Cavazzoni $^{1} \cdot$ Hania Obaid $^{1} \cdot$ Shaher Yaghi $^{2}$ \\ Accepted: 28 October 2021 \\ ๑) The Author(s), under exclusive licence to Springer Science+Business Media, LLC, part of Springer Nature 2021
}

\begin{abstract}
In the present article, we aimed at construing a new quantitative measure of children's agency in Palestine. Within a socioecological and culturally and contextually informed perspective, the study introduces the development of a new instrument to investigate and evaluate children's agentic practices within their living contexts and their daily lives. First, we evaluated the model of measurement of WCAAS-Pal using a sequential exploratory factor analysis (EFA) and confirmatory factor analysis (CFA). Following the principles of testing a quantitative measure in the context of the dual-frame sampling method, the process of validating the quantitative measure was conducted on a group of 1166 Palestinian children aged 9 to 14 years $(\mathrm{m}=11.58, \mathrm{sd}=1.54)$. Second, a sample of 251 Palestinian children aged between 9 and 14 years $(\mathrm{m}=11.82, \mathrm{sd}=1.53)$ was used to compute the reliability of the instrument along with both convergent and divergent validity using the Children Hope Scale and the Children Revised Impact of Event Scale-Arabic Version measures, respectively. The results of the EFA suggested a baseline seven-factor structure to be further assessed via CFA. a complex web of agency domains that might contribute to the child psychological functioning when forced to leave in conditions of ongoing threat and military violence emerged from the analysis.
\end{abstract}

Keywords Children agency · War · Violence · Instrument validation · War Child Agency Assessment Scale

\section{Introduction}

Within the human and social sciences, the concept of agency is nowadays considered almost a mantra (Durham, 2008). Moreover, the idea that children are not only objects of social structures and processes but also active in their construction and determination is by now well-established within the literature, placing the concept of agency among the most important theoretical contributions of the last two decades (Oswell, 2013; Prout \& James, 1990). So far, researchers have extensively documented children's competencies and abilities in playing an active role within their family, social, and community contexts and in enhancing their well-being

Guido Veronese

guido.veronese@unimib.it

1 Department of Human Sciences "R. Massa", University of Milano-Bicocca, Piazza dell'Ateneo Nuovo 1, 20126 Milan, Italy

2 Jabalia Rehabilitation Society, Jabalia, Palestine even within challenging life contexts (Abebe, 2019; Edmonds, 2019; Steckermeier, 2019; Veronese et al., 2018). Indeed, acknowledging that children 'have agency' led several scholars to highlight it in its multidimensional aspect, broadening its conception from mere personal competence to a dynamic process that develops and unfolds differently within social relations and within specific contexts and cultures (Edmonds, 2019; Cavazzoni et al., 2020; Valentine, 2011; Veronese et al., 2021). Children's agentic practices have been described and observed within their everyday activities, such as play, education and schooling (Akesson, 2015; Spyrou, 2018; Veronese et al., 2018), supported by religious and national beliefs, and acted out through and within social and community relationships (Armstrong et al., 2005; Habashi, 2011). Hence, the dimensions within which their agency unfolds have been documented as strongly connected to children's everyday life and circumstances and thus be investigated culturally and contextually sensitively (Abebe, 2019; Steckermeier, 2019; Valentine, 2011).

Although its relevance within childhood studies, the lack of a clear definition, conceptualization and 
operationalization of its core meaning is still prominent within the literature (Ibrahim \& Alkire, 2007; Settersten \& Gannon, 2005; Spyrou, 2018). While many scholars have dedicated their efforts to analyzing and exploring it in different populations and contexts, the construct is often understood differently, highlighting the lack of a single conceptualization and theory behind it. Indeed, at times this construct is associated with more purely interpersonal characteristics (e.g., self-efficacy, mastery, internal locus of control) and defined in terms of the ability to exert control over one's life and pursue goals (Beyers et al., 2003; Poteat et al., 2018). At other times, scholars have instead highlighted the need for a more comprehensive definition that also considers the opportunities and constraints structurally defined by the context in which individuals are embedded (social, cultural, material, or political context) (Abebe, 2019; Cavazzoni et al., 2020; Klocker, 2007). Thus, scholars started to conceptualize agency as that set of "ways in which individuals counteract their life course through the choices and actions they take within the opportunities and constraints of history and social circumstances' (Elder et al., 2003, p.5), emphasizing the importance of considering and theorizing agency as culturally situated and operating within structures (Elder et al., 2003; Cavazzoni et al., 2021b; Steckermeier, 2019).

Furthermore, the absence of a shared understanding of agency's meaning is also reflected in the lack of agreement on how this construct should be operationalized. On the one hand, there is a dearth of research and studies aimed at developing psychometric measures to assess agency, highlighting the presence of a still very abstract debate on the construct (Oswell, 2013; Spyrou, 2018). On the other hand, existing measures vary depending on the agency's conceptualization that scholars have assumed. For example, validated instruments for self-efficacy (General Self Efficacy Scale), mastery (Pearlin Mastery Scale), or autonomy (Adolescent Autonomy Questionnaire) have been used to assess agency in children in different contexts (Chen et al., 2001; Pearlin \& Schooler, 1978; Noom, 1999). Still, other indicators targeted externally observable agency characteristics, such as freedom of movement from one place to another (Pedaste $\&$ Leijen, 2020; Richardson et al., 2019). In a recent literature review exploring the existing tools for measuring agency within different age groups and contexts (Cavazzoni et al., 2021a), the authors highlighted the absence of shared instruments for its assessment. Moreover, they have shown how research has primarily focused on constructing and validating instruments on the adult or female population (e.g., ATPA-22, Assessment Tool for Perceived agency; WAS-61, Women's Agency Scale) (Lautamo et al., 2021; Yount et al., 2020), with few systematic efforts directed to assess children's agency (Hitlin \& Elder Jr, 2007; Veronese et al., 2019; Zimmerman et al., 2019). Among these, some attempts have addressed agency in its single aspect (e.g., political agency; agency in education) (Habashi \& Worley, 2009; Burger \& Walk, 2016; Reeve \& Tseng, 2011), while others have emphasized the need to measure it in its multidimensionality, thus investigating it within the different dimensions in which it unfolds (Richardson et al., 2019). Again, the Children Hope Scale (Snyder et al., 1996), an instrument already validated and adopted in several contexts, has been used to assess children's agency (Veronese et al., 2019; Poteat et al., 2018). Rooted in Snyder's conceptualization of the hope construct, agency is understood as a global belief in one's ability to do and achieve goals (Snyder et al., 1996). Criticized for its lack of contextual and cultural sensitivity, other authors have attempted to grasp agency through the constructs of optimism, self-efficacy, and planfulness, or with concepts such as "the person's ability to express their voice", freedom of movement, and decision making, developing ad hoc tools (Hitlin \& Elder Jr, 2007; Zimmerman et al., 2019).

These few attempts to operationalize the construct reveal a lack of comprehensive measurements to assess agency that is culturally and contextually informed and thus inclusive of connections to the social, cultural, physical, and political characteristics of the contexts where children inhabit (Eteläpelto et al., 2013; Hitlin \& Long, 2009; Ibrahim \& Alkire, 2007; Spyrou, 2018; Pedaste \& Leijen, 2020). Hence, we aimed to construct a new quantitative measure of children's agency in Palestine with this work. Within a socio-ecological and culturally and contextually informed perspective, the study presents the development of a new instrument to investigate and evaluate children's agentic practices within their living contexts and their daily lives.

\section{The Study}

The main aim of the present study was to present the process of construction of a new quantitative measure (War Child Agency Assessment Scale, Palestinian version - WCAASPal) for measuring agency in Palestinian children exposed to political and military violence. Within the Palestinian context, children have been depicted to be actively involved in assigning meaning to their reality and promoting their psychological well-being and functioning (Cavazzoni et al., 2020; Veronese et al., 2018). In clinical psychology, it is possible to find several studies uncovering the multidimensional aspects of children's agency, depicting it as a psychological source for mobilizing survival skills and personal well-being among children (Veronese et al., 2018). Indeed, their agentic practices have been documented within the sphere of the family and community, commitment to school and education, daily recreational activities - as well as civic and political commitment to the liberation of their country from the occupying and oppressive colonizer (Barber, 2008; Veronese 
et al., 2018). However, while qualitative research aimed at observing Palestinian children's agency and well-being has been increasingly consistent over the years, at present, no systematic efforts have been made to define and measure it with contextually, clearly, and conceptually informed items (Hitlin \& Elder Jr, 2007; Zimmerman et al., 2019). In this sense, developing a quantitative measure for agency in children living in areas of conflicts or military violence allows an instrument for evaluating and planning on-site intervention programs and clinical activities.

\section{Background}

The Palestinian population has been living under military occupation since the 1948 war, which worsened in ' 67 ; daily life has been characterized by ongoing experiences of extreme violence, trauma, and severe human rights violations (Human Rights Watch, 2019). The situation has only deteriorated over time. The barrier built by Israel in the West Bank isolates towns and villages, severely restricting Palestinians' freedom of movement and access to rights such as work, education, and health (Amnesty International, 2020) and increasing inaccessibility to treatment in a pandemic situation such as covid-19. Gaza is enclosed for the 14th year in a strip in an illegal air, land, and maritime blockade (Amnesty International, 2020). The goods' entry and people are controlled and restricted, with a devastating impact on the lives of 2 million inhabitants in Gaza, already severely stretched by the many military attacks over the years. In addition, Israel has continued to impose institutionalized discrimination, forcing the displacement of hundreds of Palestinians in the West Bank and East Jerusalem, following the demolition of homes and other coercive measures (Amnesty International, 2020). As a consequence of such dispossession policies, the refugees' number represents $73.1 \%$ of the population of the Gaza Strip and 30.2\% of the West Bank (PCBs, 2016).

The situation throughout the Palestinian territories has been dramatically exacerbated by the spread of the Covid-19 pandemic, severely affecting both the West Bank and the Gaza Strip. The conflict severely compromises the possibility of implementing social distancing and essential hygiene measures (OECD, 2020). Indeed, in Gaza, health systems already damaged by the blockade and bombing lack medicines, equipment, and professional staff, making it impossible to contain the virus and raising Covid mortality rates. To date (June 2021), there are over 330,000 registered cases of Covid-19 in the Palestinian territories, with 3777 deaths between the West Bank and Gaza Strip (WHO, 2021).

\section{Methodology}

\section{Study Design}

Data were cross-sectionally collected from March 2020 to May 2021, both in West Bank, Gaza Strip, and East Jerusalem, the three main geographical areas constituting the occupied Palestinian territory (Handel, 2009). Moreover, the present study adopted a dual-frame sampling method meaning that samples are drawn independently from two overlapping frames covering the population of interest (Lohr \& Rao, 2000).

\section{Sample}

A cluster sampling procedure (Teddlie \& Yu, 2007) included children according to age, gender, degree of exposure to military violence, geographical distribution in Palestine. Participants were purposively selected through convenience sampling in school institutions belonging to the governmental, private sectors, and ruled by the United Nations-affiliated body in refugee camps all over the Palestinian territories, the UNRWA schools (United Nations Relief and Work Agency).

The sample size was calculated using a confidence level of $95 \%$ and a $5 \%$ margin of error on a total population of 2,115,370 children living in the occupied Palestinian territory, resulting in ideal samples of 385 children; moreover, we determined 20 cases for each item reaching a level of about 1000 participants (Brown, 2015). Besides, in the literature on scales validation, we found specific recommendations of 250 to 500 participants, and we tried to adhere to such a suggestion as minimum bases (Lewis, 2017; Schumacher \& Lomax, 2010).

The first sample (A) was composed of 1166 Palestinian children aged 9 to 14 years $(m=11.58, \mathrm{sd}=1.54)$. Children were recruited in different primary and lower secondary school locations covering three governorates in West Bank (Nablus, Jericho, and Bethlehem) and Jerusalem. Approximately $50 \%$ of participants were boys $(n=586)$. Children were attending the following school grades: 5th grade ( $n=120$ and $10.3 \%), 6$ th grade $(n=205$ and $17.6 \%), 7$ th grade $(n=244$ and $20.9 \%), 8$ th grade $(n=213$ and $18.3 \%)$, 9 th $(n=235$ and $20.2 \%)$ and 10th $(n=149$ and $12.8 \%)$. The second sample (B) was composed of 251 Palestinian children aged between 9 and 14 years $(m=11.82, \mathrm{sd}=1.53)$ recruited in primary and lower secondary schools located in the Gaza Strip. Similarly to sample A, approximately $50 \%$ of participants were boys $(n=123)$. Children were attending the following school grades: 5 th grade $(n=16$ and $6.4 \%), 6$ th grade $(n=40$ and $15.9 \%), 7$ th grade $(n=54$ 
and $21.5 \%), 8$ th grade $(n=50$ and $19.9 \%)$, 9th $(n=43$ and $17.1 \%)$ and 10th $(n=48$ and $19.1 \%)$. The inclusion criteria for the present study (both samples) were being aged between 9 and 14 years at the study time and being Palestinian. Exclusion criteria were not being previously diagnosed with any psychological or psychical syndromes.

\section{Procedure}

Before taking part in the study, written parental consent was requested and obtained from all children and their families. Participants and their families were both openly informed about the aim and the objectives of the study. All the data were collected anonymously, and the information was analyzed in an aggregate manner. Participation in the study was free, and no monetary or other incentives were offered. Local psychologists and researchers trained in the social sciences administered the research protocol in the classroom during school hours. Participants were free to withdraw from the study at any time. Completion of the research protocol took $40 / 50 \mathrm{~min}$. The settings where it was administered were designed to offer a relational space (Hydén, 2014) in which participants would feel free to express their perceptions and opinions (Veronese et al., 2016). All phases of the research were conducted following the ethical guidelines of the American Psychological Association (American Psychological Association, 2010) and the principles enshrined in the Declaration of Helsinki (World Medical Association, 2013). None of the authors reported any financial or other conflicts of interest with the research aims and outcomes. Ethical approval was obtained from the Institutional Review Board of the University of Milano-Bicocca (Protocol N. 368).

\section{Questionnaire and Item Development}

In terms of questionnaire development, eliciting children's voices (e.g. understanding how they live their lives, how they perceived their living spaces or acting as social actors from a bottom-up perspective) was central in exploring how they deal with their living circumstances. As Lieten (2008) stated, "close reading is needed with a focus on the daily lives of children, their cognitive understanding and emotional reactions, their interactions with each other and with adults of various kinds, and their strategies of action" (p. xvi). Many textbooks reported about children' agency predominantly from a Western-oriented position [see for instance Corsaro, 2009 or Qvortrup, 2005], consequently, to understand the cultural-specific bases of agency in Palestinian children, the first step was to necessarily interrogate them through an in-depth semi-structured interview (Stage 1). To this end, interviews were conducted with 75 children (7-13 years old, $\mathrm{m}=10.27, \mathrm{sd}=1.38,68 \%$ female) coming from different contexts in the West Bank and Gaza (i.e., rural areas, urban areas, refugee camps), all attending primary school. Interviews aimed at observing and investigating children's everyday agentic practices (Payne, 2012). Through a highly participatory methodology (interactive maps, walk-along interviews), children were asked to draw and then describe a map of their everyday places, both safe and unsafe, to understand better how the places represented were either enhancing or suppressing their agency. Upon completing the drawing task, 30 children (40\%) were asked to guide the researchers inside the represented places to continue the interview, allowing an in-depth investigation of children's agentic practices in their daily lives (walk-round technique, Anderson, 2009). The areas of inquiry investigated included: descriptive information (e.g., describe the place); emotions (e.g., how do you feel in this place?); behavioural information (e.g., how do you spend your time here), and relational information (e.g., do you come to this place alone?) (for a full description, see Cavazzoni et al., 2021b).

After conducting the interviews with children, the next step was to translate all recorded materials into English (Stage 1b; see Fig. 1 for the complete process). In translating, we followed the standard procedures of forward-and-backtranslation (Brislin, 1970). As a result, two practitioners with a background in psychological research methods provided an initial conceptual translation of children's words. They were fluent in English and familiar with English-speaking cultures; simultaneously, they were native Arabic speakers in the target Palestinian culture. The research output of this phase was having a complete set of transcribed interviews translated in English in order to analyze the material for 1) identifying main dimensions of war children agency (i.e., conceptualizing the construct of agency from children voices) and 2) defining empirical indicators for saturating each dimension (i.e., operationalizing the constructs by developing a set of items).

Next, four collaborative discussion sessions with eight experts from the field, clinical psychologists, key informants, and PhD students were organized. In the first two sessions (Stage 2a), eight domains of children agency were mapped (social aspects, education, safety and security, freedom of movement, religion, and spirituality, national identity, play and leisure, living and political environment) by using bottom-up thematic analysis (Boyatzis, 1998) to analyze interviews. The other two sessions (Stage $2 b$ ) were planned to develop approximately items covering different facets of each dimension. For instance, for the domain "freedom of movement", experts worded items such as "I feel free when I am able to reach my destination by myself" or "I can go to places on my own". At the end of this study stage, a set of 109 items was finally developed and screened by a panel of three Arab-native speaking and Palestinian academics (Stage 3). Each external reviewer was asked to rate from 1 (not appropriate) to 5 (totally appropriate) the 


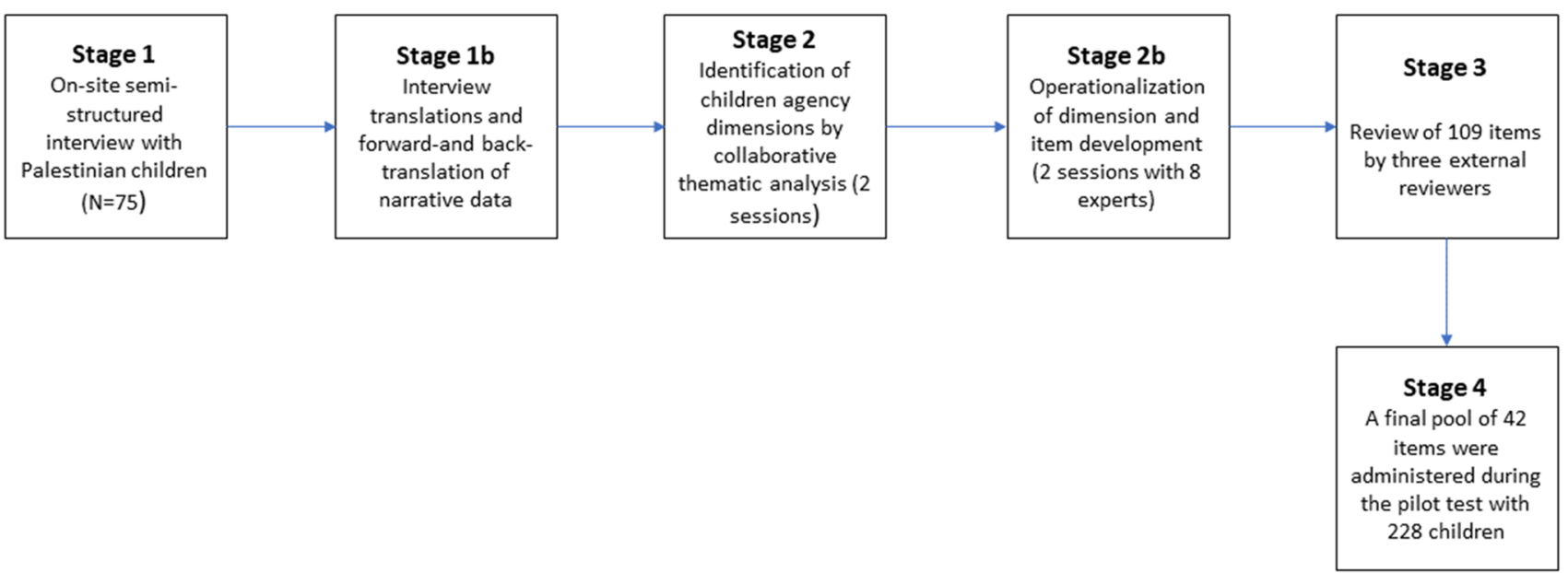

Fig. 1 Summary of stages in the development of the WCAA-Pal: from children voices to empirical indicators (42 items)

degree to which the item was pertinent in measuring agency in such a cultural context. Cultural salience underpins the formation of semantic domains, defined as "organized set[s] of words, concepts, or sentences, that jointly refer to a single conceptual sphere" (Weller \& Romney, 1988, p. 9). In addition, each item was also commented on in terms of cultural appropriateness, quality of the wording, and redundancy. After receiving all the reviewers' assessments, the only items reporting a minimum mean score of four or more were retained. As a result, a set of 42 items covering the initially identified eight dimensions was retained. During stage 4, 228 Palestinian children were involved in the onsite pilot study to evaluate preliminary statistical proprieties (e.g., distribution of scores, checking for potential floor or ceiling effects, missing rates) of the WCAAS-Pal (e.g., on the pool of 42 items). The sample was composed of $54 \%$ of boys $(n=123)$ aged between 9 and 14. The data-gathering phase followed the criteria described in the procedure section of the present article. Analysis of scores revealed items with highly skewed distribution (i.e., mainly ceiling effect, meaning that a high rate of children has maximum scores on the observed variable). Items excluded were: "I want to learn in order to have a job and enhance my future opportunities", "I want to go to school to be successful in my life", "I choose to go to school because it is my right to obtain an education" and "When something bad happens, I prefer to stay close to my family".

\section{Measure}

War Child Agency Assessment Scale - Palestinian version (WCAAS-Pal): the questionnaire was developed to evaluate agency in children from a multidimensional perspective. The questionnaire score reflected different domains of children's agency as emerged from a bottom-up exploratory multi-method approach. The scale consists of items rated on a Likert-type scale ranging from 1 (not at all) to 5 (very much). Sample items include "I can identify places that I enjoy and that are relaxing", "I prefer to avoid places that remind me of the martyrs", and "Discovering things about the world helps me feel in control of my life".

Children's Hope Scale (CHS; Snyder et al., 1996): The Children Hope Scale was a quantitative measure assuming that children are goal-oriented, and it was composed of two domains: agency and pathways. Agency thoughts reflect the perception that children can initiate and sustain action toward a desired goal; pathways reflect the children's perceived capability to produce routes to those goals (Snyder et al., 1996). Hope reflects the combination of agentic and pathways thinking toward goals. As a result, a six-item dispositional self-report index was validated for use with children ages 8-16. The scale consists of items rated on a Likert-type scale ranging from 1 (none of the time) to 6 (all the time). Sample items included: "I think I am doing pretty well", "When I have a problem, I can come up with lots of ways to solve it", and "I am doing just as well as other kids my age". The scale was administered in Arabic, following the standard forward- and back-translation (Brislin, 1970). Reliability score (Cronbach's alpha, Cronbach, 1951) for the two domains were: agency $(\alpha=.687)$ and pathway $(\alpha=.680)$.

Children Revised Impact of Event Scale-Arabic Version (CRIES-13A; Veronese \& Pepe, 2021): The Children Revised Impact of Event Scale-Arabic Version was an adapted version of the Impact of Event Scale (Dyregrov et al., 2018) for the evaluation of traumatic psychological responses in children who have been exposed to ongoing traumatic events in contexts of violence. The original measurement model comprised three dimensions: intrusion, avoidance, and hyperarousal. Items are rated on a four-point 
scale $(0=$ not at all, $5=$ often $)$. Sample items included: "Do you think about erasing the event that shocked you from your memory?", "Do you have difficulty concentrating?" and "Do you try to avoid thinking about the shocking event?". Reliability score (Cronbach's alpha, Cronbach, 1951) for the three domains were: intrusion $(\alpha=.738)$, avoidance $(\alpha=.715)$ and hyperarousal $(\alpha=.732)$.

\section{The Strategy of Data Analysis}

The exploration of the War Child Agency Assessment Scale - Palestinian version's (WCAAS-Pal) measurement model, followed standard procedures for validating quantitative self-reports (Matsunaga, 2010; Mertler \& Reinhart, 2016). This means that we evaluated the model of measurement of WCAAS-Pal using a sequential exploratory factor analysis (EFA) and confirmatory factor analysis (CFA).

\section{EFA Results}

The results of the EFA suggested a "baseline" factor structure to be further assessed via CFA. Given the ordinal nature of the scores (Likert-type response scale), EFA was conducted on the polychoric matrix (Holgado-Tello et al., 2010) of correlations computed using Lorenzo-Seva and Ferrando's (2015) syntax for SPSS. We also conducted the KaiserMeyer-Olkin (KMO) test and Bartlett's test of sphericity (Field, 2009). Parallel analysis eigenvalues were estimated using Monte Carlo PCA for Parallel Analysis 2.3 (Watkins, 2008). Velicer's minimum average partials (MAPs) were computed using O'Connor (2000) program developed ad hoc for SPSS. The EFA comprised estimation via principal axis factoring (Briggs \& MacCallum, 2003) and oblimin rotation (Darton, 1980). We applied Kaiser's criterion (K1; Kaiser, 1960) to identify the most appropriate number of factors to be retained and parallel analysis (Horn, 1965) to further inform our decisions about the most appropriate factor structure for our adapted version of the questionnaire. Parallel analysis (PA) is a data simulation technique that compares the eigenvalues of the factors extracted from the observed data with random data matrices of comparable size (Hayton et al., 2004). We also estimated Velicer's MAPs (Velicer et al., 2000). Caron (2018) observed that MAP offers a more accurate indication of the most appropriate number of factors than PA when the component structure is moderately oblique. Therefore, we only adopted factor loadings ( $\lambda$ ) greater than .40 (Hair et al., 2006), dropping items that loaded on more than one factor (Costello \& Osborne, 2005).

\section{CFA Results}

The measurement model identified from the EFA was next explored to CFA to evaluate further evidence of construct validity (Gagne \& Hancock, 2006). CFA was a statistical technique that supported the development of quantitative tools by testing a given measurement model's degree of fit with empirical data (Kline, 2010). In the present paper, the following absolute and relative fit indexes were adopted: $\chi 2$, normed chi-square (NC), root mean square error of approximation (RMSEA), standardized root mean square residual (SRMR), Nor-Normative Fit Index (NNFI), and comparative fit index (CFI). Model fit was taken to be accepted if NC was $<3.0$, RMSEA $<.08$, SRMR $<.08$, NNFI and CFI $>.95$ (Morin et al., 2013). Finally, the Akaike information criterion (AIC) was adopted to compare models. First, as recommended by Hattie (1985), a unidimensional solution was estimated (with all indicators loading on a single factor, Model 1), and then the baseline model (Model 2) was specified (seven latent variables and 22 empirical indicators).

The subsequent stage of statistical analysis involved using multiple-group CFA (MGCFA; Byrne, 1998) to test the factor structure of the questionnaire in gender-based cohorts of participants to enhance the ecological validity of the results (Cavioni et al., 2020). Measurement invariance between boys and girls was to be supported when configural invariance (when the same items are associated with the same factors in each group), metric invariance (when factor loadings are set to be equal across groups), scalar invariance (when factor loadings and item intercepts are constrained to be equal across groups), and full invariance (when factor loadings, item intercepts, and residuals are constrained to be equal across groups) were accepted. We set the cutoff criteria for rejecting invariance at $\Delta>.01$ for both $\Delta$ RMSEA and $\Delta$ SRMR (Chen, 2007) and a chi-square difference $(\Delta \chi 2)$ that was statistically significant at the $p<.01$ level (Milfont $\&$ Fischer, 2010). The different types of invariance are hierarchically ordered, meaning that the MGCFA procedure ends at the lowest level of invariance that fails to be satisfied (for further details, see Cheung \& Rensvold, 2002). We also estimated Mahalanobis' distance $(\mathrm{p}<0.001)$ to detect potentially multivariate outliers; no cases needed to be removed from the dataset. Analysis of missing values revealed a mean score of $1 \%$ for blank data; consequently, missing values were replaced at random (Donders et al., 2006). Statistical Package for the Social Sciences 25.0 (SPSS; Pituch \& Stevens, 2015) and Analysis of Moment Structure 25.0 (AMOS; Arbuckle, 2011) software were used. Following the principles of testing a quantitative measure in the context of the dual-frame sampling method, the process of validating the quantitative measure (EFA, CFA, and MGCFA) was conducted on sample A (e.g., the training sample) composed of a large sample size. Then, sample B (e.g., testing sample) was used to compute the reliability of War Child Agency Assessment Scale - Palestinian version (WCAAS-Pal) scores along with both convergent and divergent validity. For convergent validity (i.e., convergent validity established 
construct validity using different measurement procedures to collect data about the same construct; Campbell \& Fiske, 1959), WCAAS-Pal scores correlated with Children Hope Scale measures. For divergent validity (i.e., divergent validity establishes construct validity by supporting the idea that the construct of interest is different from other constructs that might be present in the study), WCAAS-Pal scores were correlated with Children Revised Impact of Event ScaleArabic Version measures (e.g., psychological symptoms related to the exposure of potentially traumatic events).

\section{Results}

\section{Exploratory Factor Analysis}

Exploratory factor analysis was performed on the pool of 38 items remaining from stage 4 of preliminary analysis. The KMO $(\mathrm{KMO}=.805)$ and Bartlett's test outcomes $(\chi 2=3917.2, p<.001)$ suggested that the data were suitable for structure detection. Comparing EFA results with the random eigenvalues generated by the parallel analysis (see Table 1) suggested adopting a seven-factor structure. The same solution was supported by both the original and revised MAPs (O'Connor, 2000). A closer inspection of the oblimin rotation solution revealed that eight items did satisfy the criteria for acceptance (i.e., $\lambda>.40$ ) and other seven saturated on other factors exceeding the seven-play-factor suggested structure, so the other 22 items were used for the measurement model and EFA was again conducted to explore statistical proprieties of the remaining pool (See Table 1).

Seven different components were found, explaining approximately $46 \%$ of the variance. Of the specified initially eight domains of agency, seven were supported from the analysis of data (political agency and national identity, agency on free movement, agency on political and military violence, agency on religion and spirituality, agency on play and leisure, social agency, agency in education). In contrast, the last one was not

Table 1 Results of exploratory factor analysis on War Children Agency Assessment Scale: pattern and structural coefficients

\begin{tabular}{|c|c|c|c|c|c|c|c|}
\hline Item & Factor1 & Factor2 & Factor3 & Factor4 & Factor5 & Factor6 & Factor7 \\
\hline 17. I protest in order to end the occupation. & .665 & & & & & & \\
\hline 18. I feel hopeful when thinking about the possible end of the occupation. & .644 & & & & & & \\
\hline $\begin{array}{l}\text { 29. Whenever I wave a Palestinian flag, I feel that we are all struggling for } \\
\text { freedom in Palestine. }\end{array}$ & .580 & & & & & & \\
\hline 28. I want to learn how to resist and struggle for our freedom. & .528 & & & & & & \\
\hline 20. I feel happy because I can plan to walk alone in my neighborhood. & & 690 & & & & & \\
\hline 32. I feel in control when I am able to reach my destination by myself. & & .536 & & & & & \\
\hline 42. Discovering things about the world helps me feel in control of my life. & & .434 & & & & & \\
\hline $\begin{array}{l}\text { 4. When I don't understand what is going on in my country, I feel helpless and } \\
\text { I don't know what to do. }\end{array}$ & & & .725 & & & & \\
\hline 3. I prefer to avoid places that remind me of the martyrs. & & & .618 & & & & \\
\hline 15. When I see the Israeli army, I feel that I am unable to control my own life. & & & .615 & & & & \\
\hline 19. I decide to go to a mosque/church in order to feel safe. & & & & .885 & & & \\
\hline 22. I choose to go to a mosque/church to feel comfortable and happy. & & & & .882 & & & \\
\hline 16. Praying makes me feel closer to God. & & & & .442 & & & \\
\hline 14. I can identify places that I enjoy and that are relaxing. & & & & & .652 & & \\
\hline 13. I can find people/friends that I can play with. & & & & & .523 & & \\
\hline 11. I can choose to play outside my home. & & & & & .459 & & \\
\hline 36. I can ask my neighbor if I need help because we take care of each other & & & & & & .768 & \\
\hline 27. In my neighborhood, we all do things to help each other. & & & & & & .698 & \\
\hline 10. I choose to ask for help from people when I feel that I am not safe. & & & & & & .473 & \\
\hline 25. I choose to go to school to improve myself and my skills. & & & & & & & .452 \\
\hline $\begin{array}{l}\text { 23. I want to go to school in order to have chances to travel outside my coun- } \\
\text { try. }\end{array}$ & & & & & & & .447 \\
\hline 12. I want to go to school in order to help my family in the future. & & & & & & & .446 \\
\hline Eigenvalues from parallel analysis $(\mathrm{k}=500$ sample $)$ & 1.35 & 1.32 & 1.28 & 1.26 & 1.23 & 1.21 & 1.18 \\
\hline Actual Eigenvalues from factor analysis & 5.14 & 2.04 & 1.65 & 1.48 & 1.40 & 1.29 & 1.20 \\
\hline Explained variance & 15.96 & 6.42 & 5.53 & 5.21 & 4.58 & 4.26 & 4.17 \\
\hline Cumulate variance & 15.96 & 22.37 & 27.91 & 33.12 & 37.70 & 41.96 & 46.13 \\
\hline
\end{tabular}

$\mathrm{KMO}=0.805 ;$ Bartlett's test $=3917.1 ; h 2=$ communalities; $u 2=$ uniqueness. $\mathrm{KMO}=$ Kaiser-Meyer-Olkin 
included in the structure (safety and security). The resulting measurement model (seven factors, 22 items) was used as the baseline for the subsequent analyses.

The unidimensional model (M1) reported a mediocre fit for the data: $\chi 2(209)=1400.4, p<.001, \mathrm{NC}=6.70, \mathrm{NNFI}=.559$ $\mathrm{CFI}=.601, \mathrm{RMSEA}=.070, \mathrm{SRMR}=.061, \mathrm{AIC}=1315.2$. Next, the baseline factor structure was specified (see Fig. 1) and it reported an acceptable fit, $\chi^{2}(188)=564.4, p<.001$, $\mathrm{NC}=3.00, \mathrm{NNFI}=.845, \mathrm{CFI}=.874, \mathrm{RMSEA}=.041$, $\mathrm{SRMR}=.043$ and $\mathrm{AIC}=738.4$ (See Fig. 2). It is worth noting here that only the incremental fit index (i.e., NNFI and CFI) did not reach the cut-off values for acceptance while, on the contrary, the absolute fit indexes were above the recommended bund for acceptance. In cases like this, a possible explanation can be found in the general level of correlations among empirical indicators. As Kenny (1985) pointed out, in databases presenting non particularly high inter-correlations it is possible that incremental fit indexes underperformed.

The MGCFA provided strong bases for accepting the invariance of the measure between boys and girls about the seven dimensions of the measurement model (see details in Table 2). Results indicated that $\chi 2$ increased between steps, but model comparison steps never reached statistically significant variation. Nevertheless, CFI and RMSEA changes were below Cheung and Rensvold (2002) cutoff. From configural invariance to full invariance, all statistical indicators supported the idea that it would be reasonable to conclude that the measurement model represented both groups of children and endorsed the use of the questionnaire in drawing inferences from differences in latent means and sum scores between gender-based groups (Byrne et al., 1989).

Reliability and zero-order correlations of WCAAS-Pal scores with other measures of agency and psychological consequence of being exposed to potentially traumatic events were reported in Table 3.

Regarding convergent validity, almost all the WCAASPal scales positively correlated with both measures of CHS (agency and pathways). In particular, zero-order correlations ranged from $(\mathrm{r}=.251, \mathrm{p}<.001)$ between social aspects and hope and $(\mathrm{r}=.133, \mathrm{p}<.05)$ between freedom of movement and pathway. In general, the patterns of associations provided support for convergent validity of WCAAS-Pal with Children Hope Scale measures. On the other hand, the set of zero-order correlations between agency and traumatic psychological responses in children did not report statistically significant associations, thus supporting divergent validity.

\section{Discussion}

We sought to construe and validate a new and, to our knowledge, the first instrument capable of assessing and measuring children's agentic competencies in the war-torn environment of Palestine (AUTHOR, submitted). According to previous literature, the instrument's dimensions emerging from the factor analysis showed and confirmed the ecological and multilevel nature of agency construct in children affected by war and military violence, the factorial structure of the instrument revealed a complex web of agency domains that might contribute to the child psychological functioning when forced to leave in conditions of ongoing threat and military violence (Strang \& Wessells, 2006).

\section{Factor Structure and Agency's Domains}

The first factor of the instrument, political agency and national identity ( F1), enlightened a binding domain of agency that can help children perceive and regain control in war and structural violence conditions. Activism and the political participation of children as a form of resilience and survival skill have been widely studied in the Palestinian context and worldwide (Barber et al., 2014; Boyden, 2003; Spellings et al., 2012; Veronese et al., 2017a, 2017b). The national struggle against an occupying force seems to provide children with a sense of mastering their lives and the psychological benefit of feeling their participation as active social actors in a community resisting the ongoing military occupation (Massad et al., 2018; Veronese \& Cavazzoni, 2020).

The second factor, agency on free movement ( $F 2)$, relied on fundamental rights for children, their need to move in a free and safe place as a pivotal domain for healthy child development (Pinkard, 2019). In the particular context of Palestine, where the human landscape and child geography are constellated by military fences, checkpoints, separation walls, and obstacles in travelling within and outside the country, children's agency on their free movement emerged as a construct's key-domain and robust factor at WCAAS-Pal score. Accordingly, freedom of movement for Palestinian children has been studied as a crucial component enacting psychological well-being and adjustment to potentially traumatic events (Sousa et al., 2019; Veronese et al., 2020a, 2020b).

The third factor (agency on political and military violence, F3) showed the pervasive effect of military violence on children's lives in Palestine (Qouta et al., 2008; Wilson et al., 2021). Thus, children's agentic behaviours are forcibly oriented at mitigating the effects of pervasive violence on their lives. This factor strongly correlates with activism and political activities to cope with the social suffering of Palestinian society. Accordingly, children try to adjust to the presence of soldiers, police constantly, and surveillance systems threatening their lives and development, finding strategies to survive systematic violence and political oppression (Mahamid, 2020; Mahamid \& Veronese, 2020; Veronese et al., 2020a, 2020b). 
Fig. 2 Confirmatory factor analysis: measurement model of War Child Agency Assessment Scale - Palestinian version (WCAAS-Pal). Standardized saturation values were reported

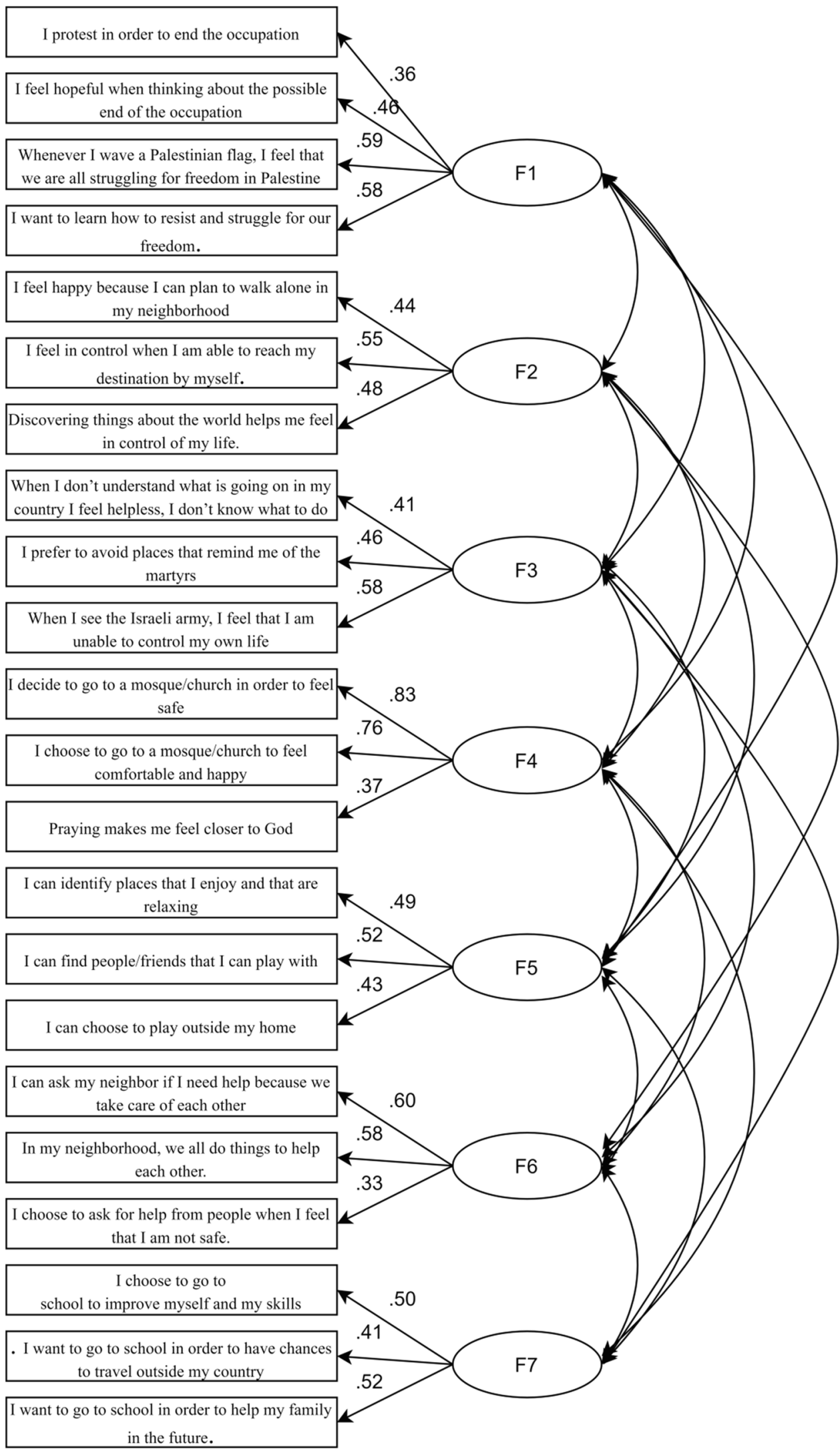


Table 2 Multigroup analysis of the War Child Agency Assessment Scale - Palestinian version (WCAAS-Pal) between girls and boys

\begin{tabular}{|c|c|c|c|c|c|c|c|c|c|}
\hline Type & $\chi^{2(\mathrm{df})}$ & CFI & RMSEA & RMSEA $90 \%$ C.I. & $\begin{array}{l}\text { Model } \\
\text { Compari- } \\
\text { son }\end{array}$ & $\Delta \chi^{2}(\Delta \mathrm{df})$ & $\Delta \mathrm{CFI}$ & $\Delta$ RMSEA & Decision \\
\hline M1. Configural Invariance & $802.61(367)$ & .860 & .031 & [.028- .034] & - & - & - & - & Accept \\
\hline M2. Metric Invariance & $831.78(391)$ & .856 & .032 & {$[.048-.034]$} & M1 & $29.17(24)$ & .004 & .001 & Accept \\
\hline M3. Scalar Invariance & $841.39(413)$ & .860 & .030 & {$[.027-.033]$} & M2 & $9,61(22)$ & .004 & .002 & Reject \\
\hline M4. Full Invariance & $872.21(441)$ & .859 & .029 & {$[.026-.032]$} & M3 & $30.81(28)$ & .001 & .001 & Reject \\
\hline
\end{tabular}

$\mathrm{df}=$ degree of freedom, $\mathrm{CFI}=$ Comparative fit index, RMSEA = Root Mean Square Error of Approximation, C.I. = Confidence Interval

Table 3 Reliability, convergent and divergent validity of WCAAS-Pal scores in relation to the testing sample $(n=251)$

\begin{tabular}{|c|c|c|c|c|c|c|c|c|c|c|c|c|}
\hline & 1 & 2 & 3 & 4 & 5 & 6 & 7 & 8 & 9 & 10 & 11 & 12 \\
\hline 1. National Identity & - & & & & & & & & & & & \\
\hline 2. Freedom of movement & $.216^{* *}$ & - & & & & & & & & & & \\
\hline 3. Living and political environment & .013 & .075 & - & & & & & & & & & \\
\hline 4. Religion and spirituality & $.352 * *$ & $.237 * *$ & .066 & - & & & & & & & & \\
\hline 5. Play and leisure & $.248 * *$ & $.309 * *$ & .101 & $.155^{* *}$ & - & & & & & & & \\
\hline 6. Social Aspect & $.448 * *$ & .086 & .076 & $.190 * *$ & $.194 * *$ & - & & & & & & \\
\hline 7. Education & $.291 * *$ & $.293^{* *}$ & .049 & .085 & $.208^{* *}$ & .084 & - & & & & & \\
\hline 8. Hope scale & $.189 * *$ & $.160 * *$ & .047 & .054 & $.132 *$ & $.251 * *$ & $.230 * *$ & - & & & & \\
\hline 9. Patways & $.157 * *$ & $.133 *$ & -.015 & $.133 *$ & .090 & $.239 * *$ & $.197 * *$ & $.661 * *$ & - & & & \\
\hline 10. Intrusion & .071 & .014 & -.050 & .027 & .083 & .015 & .029 & .047 & .047 & - & & \\
\hline 11. Avoidance & .068 & .028 & -.055 & .007 & .032 & .010 & .052 & .010 & .039 & $.679 * *$ & - & \\
\hline 12. Hyper-arousal & $.146^{*}$ & .040 & .046 & .112 & .020 & .051 & .017 & .059 & .080 & $.470 * *$ & $.380 * *$ & - \\
\hline Omega (reliability) & $.722^{\mathrm{b}}$ & $.452^{\mathrm{b}}$ & $.437^{\mathrm{b}}$ & $.592^{\mathrm{b}}$ & $.640^{b}$ & $.589^{\mathrm{b}}$ & $.687^{\mathrm{a}}$ & $.680^{\mathrm{a}}$ & $.738^{a}$ & $.715^{\mathrm{a}}$ & $.732^{\mathrm{a}}$ & \\
\hline
\end{tabular}

$* p<.05, * * p<.01,{ }^{\mathrm{a}}$ Cronbach's alpha; ${ }^{\mathrm{b}}$ McDonald Omega Coefficient

Moreover, Factor 4, agency on religion and spirituality, depicted the connection with spiritual and religiousinformed agentic behaviours as a protective factor safeguarding children from burdens of war and violence (Veronese et al., 2017a, 2017b; Pandya, 2018). Religiosity in a Muslim context is a crucial determinant of individuals' sense of efficacy and personal well-being. Feeling part of a religious community and the faith in God enact human flourishing and satisfaction with life (Abu-Raiya et al., 2019). It means that religion and spirituality can provide children with agency sources to protect them from hardships in Palestine (Veronese et al., 2018).

The fifth factor (agency on play and leisure, F5) indicated the crucial role of play as an agentic resource for Palestinian children (Marshall, 2013). Children face a disrupted and dangerous living environment, where it is utterly demanding to find safe places where play and relax. Accordingly, children must reinvent their playgrounds, actively construing the spaces where they can feel safe and relaxed. Conversely, being deprived of personal resources to play and express creativity might increase hopelessness and powerlessness among Palestinian children (Marshall, 2014).
The sixth factor (social agency, F.6) defines the child as an active and situated social actor within the Palestinian society (Kovner \& Shalhoub-Kevorkian, 2018). Children use social relationships to mirror their capabilities and competencies, occupying a pivotal role in their communities. Agency on the social relation assumes a more critical role in those collectivistic societies where commonality, connectedness, and social support are vital factors for personal and collective well-being (Akesson \& Grinberg, 2020).

The last factor (agency in education, F.7) showed the importance of education for children living in war-like conditions (Sinclair, 2001). In particular, Palestinian children valorize their educational opportunities as a means for resistance and existence (Diab et al., 2018; Veronese et al., 2017a, 2017b). In addition, children use school life as a means of self-expression and a source to cope with the ongoing violence.

In sum, our seven factors instrument built to detect agency in Palestinian children sought to portrait the social-ecology of such construct and its sensitivity to culture and context, from a hand, the universality of children participation in enacting their subjective well-being and life satisfaction, 
from the other (Domínguez-Serrano et al., 2019). Moreover, children living in war-torn environments are likely to be deprived of fundamental development and growth resources. Accordingly, agency might help develop survival skills and guarantee sufficient sources for adjusting to cumulative hardships.

The following section discusses the agency's role as a theoretically unique protective factor against potentially traumatic experiences.

\section{Agency as a Potential Protective Factor: The Lesson Learned from Convergent and Divergent Validity}

As discussed in the result section, WCAAS-Pal correlated in all its scales with the children's hope scale instrument, while a measure of trauma did not correlate (Belen et al., 2020). These interesting preliminary results invite us to research the potential role of agency in protecting children from traumas, buffering their mental health when exposed to war episodes and extremely violent environments (Veronese et al., 2019). Indeed, the instrument seems to confirm its construct validity correlating with a well-known and widely validated instrument that has been built to detect children's hope and pathways for the future (Snyder et al., 1996, 1997). Therefore, agency and hope can be considered constructs that can enact children's competencies and coping strategies when exposed to war and systematic violence (Dyeregov et al., 2018; Mahamid \& Berte, 2020). Agency and hope showed to be converging constructs that might help children in coping with hardships and aggression. Future research will provide further information about the relationship between the two constructs, some potential overlapping and peculiarity as showed by our study's low collinearity and WCAAS-Pal and CHS.

Research on the agency's role in protecting children's mental health during and after conflicts can be facilitated using WCAAS in its adapted forms, depending on the context, geographical area, and historical moment where research will be carried out. Possibly, WCAAS, compared to CHS (Snyder et al., 1996, 1997), showed its potentiality to capture influential culture and context-specific dimensions, acknowledging the complex and multifaceted nature of the construct of agency.

Before concluding, some limitations of the study must be underlined and discussed. First, the primary source for data collection was self-reported measures. Adopting this kind of method must be taken cautiously in the interpretation phase, especially when the respondents are children exposed to potentially traumatic events and living in war-torn environments. Long and difficult to read lists of items might shatter the quality of data collection due to exhaustion or discontinuous attention on children. Accordingly, we carefully preferred the most specific items possible, intending to reduce the children's fatigue while conserving the best accuracy in the data collection. In addition, mono-method studies lack sensitivity in detecting children's deeper feelings and life experiences. Therefore, future research should be oriented toward exploring children's agency via a multi-trait multimethod research design. Second, although the WCAAS-Pal provides a robust assessment of the multifaceted agency's construct, we cannot generalize our results. Our sample cannot fully represent the Palestinian children population as it has not been selected using a probabilistic approach and clusterized sampling. Moreover, as stated above, the use of WCAAS in other cultures will require careful adaptation to guarantee the sensitivity to specific contexts in specific historical phases.

Moreover, it is advisable to compute omega reliability to identify dimensions with measurement problems for a solid multidimensional measure. In general, Cronbach's alpha reliabilities indicators were based on the idea of tauequivalence, meaning that all factor loadings are equal, and the factor model was with uncorrelated errors. On the contrary, coefficient omega is deemed a practical alternative to coefficient alpha in estimating measurement reliability of the total scores (Deng \& Chan, 2017). Low reliability should be a significant concern, and it should be routinely examined in the context of poverty and deprivation. The findings suggest that omega below 0.80 are likely to result in classification error above $10 \%$ (i.e. $10 \%$ of the poor will be classified as not poor) (Catalán, 2019); thus, it is recommended, in clinical settings, to use a multi-trait approach including other measures for cross-validating evidence emerging from the application of the WCAAS-Pal.

Finally, we must acknowledge that an essential portion of young children (e.g., 7/8 years old) has been excluded from the study. We chose to focus on middle childhood and early adolescence for two reasons. First, we included children in a developmental stage that could allow them to understand the items' complexity and level of abstraction quickly and smoothly to pilot and test the robustness of the instrument and avoid possible bias due to the young age of the participants (Taber, 2010). Secondly, in the early phases of the instrument construction, we agreed with local experts and colleagues that the questionnaire could have been too demanding for 7-8-year-old children (as opposed to the interactive mode of the maps and walkarounds); thus, we consensually decided to move the age of administration by two years. However, in the future developments of the scale, we will determine the minimum age for its administration as a crucial part of our work.

The practical implications of this work are worthy of being discussed. In fact, an easy-to-administer and robust instrument capable of detecting children's agency in contexts of war and violence can assess resources that children can mobilize when exposed to extremely violent events. Having 
a clear picture of agentic resources in children might help clinicians orient their therapeutic work toward the empowerment of resilience, coping strategies, and skills of survival of children rather than solely focusing on symptoms containment and reduction. An approach oriented on children capabilities shows the importance to promote children active participation in the recovery process (Hart \& Brando, 2018). An instrument measuring children's agency will help social workers and educators build ad hoc participatory interventions during and after armed conflicts.

\section{Code Availability N/A}

Authors' Contributions GV planned the research, designed the methods, revised statistical analysis and wrote the article; AP did the statistical analysis and wrote the article; FC wrote the article; HO collected the data and revised the manuscript; SY collected the data and revised the manuscript.

Data Availability Due to the high risks Palestinian children are exposed to in the zones where data were collected and their sensitivity, the database will be available on request and after careful evaluation by the authors of the present research.

\section{Declarations}

Conflicts of Interest/Competing Interests All authors do not have competing interests to disclose.

Ethics Approval The research has been approved by the Institutional review board at the University of Milano-Bicocca.

\section{References}

Abebe, T. (2019). Reconceptualizing children's agency as continuum and interdependence. Social Sciences, 8(3), 81. https://doi.org/ 10.3390/socsci8030081

Abu-Raiya, H., Ayten, A., Tekke, M., \& Agbaria, Q. (2019). On the links between positive religious coping, satisfaction with life and depressive symptoms among a multinational sample of Muslims. International Journal of Psychology, 54(5), 678-686 https://doiorg.proxy.unimib.it/10.1002/ijop.12521.

Akesson, B. (2015). School as a place of violence and hope: Tensions of education for children and families in post-intifada Palestine. International Journal of Educational Development, 41, 192-199. https://doi.org/10.1016/j.ijedudev.2014.08.001

Akesson, B., \& Grinberg, O. (2020). A present absence: Representations of Palestinian children in the home. In Bringing children back into the family: Relationality, connectedness and home. Emerald Publishing Limited.

American Psychological Association. (2010). Publication manual of the APA (6th ed.). American Psychological Association.

Amnesty International. (2020). Israel and occupied Palestinian territories 2020. Scribbr. Retrieved from the internet on November, 11, 2021 at https://www.amnesty.org/en/countries/middle-east-andnorth-africa/israel-and-occupied-palestinian-territories/reportisrael-and-occupied-palestinian-territories/

Arbuckle, J. L. (2011). Amos 20 user's guide. SPSS.
Armstrong, M. I., Birnie-Lefcovitch, S., \& Ungar, M. T. (2005). Pathways between social support, family well being, quality of parenting, and child resilience: What we know. Journal of Child and Family Studies, 14(2), 269-281. https://doi.org/10.1007/ s10826-005-5054-4

Barber, B. K., Spellings, C., McNeely, C., Page, P. D., Giacaman, R., Arafat, C., et al. (2014). Politics drives human functioning, dignity, and quality of life. Social Science \& Medicine, 122, 90-102. https://doi.org/10.1016/j.socscimed.2014.09.055

Belen, H., Yildirim, M., \& Belen, F. S. (2020). Influence of fear of happiness on flourishing: Mediator roles of hope agency and hope pathways. Australian Journal of Psychology, 72(2), 165-173 https://doi-org.proxy.unimib.it/10.1111/ajpy.12279.

Beyers, W., Goossens, L., Vansant, I., \& Moors, E. (2003). A structural model of autonomy in middle and late adolescence: Connectedness, separation, detachment, and agency. Journal of Youth and Adolescence, 32(5), 351-365. https://doi.org/10.1023/A:10249 22031510

Boyatzis, R. E. (1998). Transforming qualitative information: Thematic analysis and code development. Sage.

Boyden, J. (2003). Children under fire: Challenging assumptions about children's resilience. Children Youth and Environments, 13(1), $1-29$.

Briggs, N. E., \& MacCallum, R. C. (2003). Recovery of weak common factors by maximum likelihood and ordinary least squares estimation. Multivariate Behavioral Research, 38(1), 25-56. https:// doi.org/10.1207/s15327906mbr3801_2

Brislin, R. W. (1970). Back-translation for cross-cultural research. Journal of Cross-Cultural Psychology, 1(3), 185-216. https:// doi.org/10.1177/135910457000100301

Brown, T. A. (2015). Confirmatory factor analysis for applied research (2nd ed.) Guilford.

Burger, K., \& Walk, M. (2016). Can children break the cycle of disadvantage? Structure and agency in the transmission of education across generations. Social Psychology of Education, 19(4), 695-713. https://doi.org/10.1007/s11218-016-9361-y

Byrne, B. M. (1998). Structural equation modeling with LISREL, PRELIS, and SIMPLIS: Basic concepts, applications, and programming. Lawrence Erlbaum.

Byrne, B. M., Shavelson, R. J., \& Muthén, B. (1989). Testing for the equivalence of factor covariance and mean structures: The issue of partial measurement invariance. Psychological Bulletin, 105(3), 456. https://doi.org/10.1037/0033-2909.105.3.456

Caron, P. O. (2018). Minimum average partial correlation and parallel analysis: The influence of oblique structures. Communications in Statistics - Simulation and Computation, 48(7), 2110-2117. https://doi.org/10.1080/03610918.2018.1433843

Catalán, H. E. N. (2019). Reliability, population classification and weighting in multidimensional poverty measurement: A Monte Carlo study. Social Indicators Research, 142(3), 887-910. https://doi.org/10.1007/s11205-018-1950-z

Cavazzoni, F., Fiorini, A., \& Veronese, G. (2020). Alternative ways of capturing the legacies of traumatic events: A literature review of agency of children living in countries affected by political violence and armed conflicts. Trauma, Violence, \& Abuse, 1-12. https://doi.org/10.1177/1524838020961878

Cavazzoni, F., Fiorini, A. \& Veronese, G. (2021a). How do we assess how agentic we are? A literature review of existing instruments to evaluate and measure individuals' agency. Social Indicators Research. https://doi.org/10.1007/s11205-021-02791-8.

Cavazzoni, F., Fiorini, A., Sousa, C., \& Veronese, G. (2021b). Agency operating within structures: a qualitative exploration of agency amongst children living in Palestine. Childhood, 28(3), 363-379. https://doi.org/10.31124/advance.12458501

Cavioni, V., Grazzani, I., Ornaghi, V., Pepe, A., \& Pons, F. (2020). Assessing the factor structure and measurement invariance of the test of 
emotion comprehension (TEC): A large cross-sectional study with children aged 3-10 years. Journal of Cognition and Development, 21(3), 406-424. https://doi.org/10.1080/15248372.2020.1741365

Chen, F. F. (2007). Sensitivity of goodness of fit indexes to lack of measurement invariance. Structural Equation Modeling, 14(3), 464-504. https://doi.org/10.1080/10705510701301834

Chen, G., Gully, S. M., \& Eden, D. (2001). Validation of a new general self-efficacy scale. Organizational Research Methods, 4(1), 62-83. https://doi.org/10.1177/109442810141004

Cheung, G. W., \& Rensvold, R. B. (2002). Evaluating goodness-of-fit indexes for testing measurement invariance. Structural Equation Modeling, 9(2), 233-255. https://doi.org/10.1207/s1532 8007 sem0902_5

Corsaro, W. A. (2009). Peer culture. In The Palgrave handbook of childhood studies (pp. 301-315). Palgrave Macmillan. https:// doi.org/10.1057/9780230274686.

Costello, A. B., \& Osborne, J. W. (2005). Best practices in exploratory factor analysis: Four recommendations for getting the most from your analysis. Practical Assessment, Research, and Evaluation, 10(7), 1-9. https://doi.org/10.4135/9781412995627.d8

Cronbach, L. J. (1951). Coefficient alpha and the internal structure of tests. Psychometrika, 16(3), 297-334. https://doi.org/10.1007/ bf02310555

Deng, L., \& Chan, W. (2017). Testing the difference between reliability coefficients alpha and omega. Educational and Psychological Measurement, 77(2), 185-203. https://doi.org/10.1177/00131 64416658325

Diab, S. Y., Palosaari, E., \& Punamäki, R. L. (2018). Society, individual, family, and school factors contributing to child mental health in war: The ecological-theory perspective. Child Abuse \& Neglect, 84, 205-216. https://doi.org/10.1016/j.chiabu.2018.07.033

Domínguez-Serrano, M., del Moral-Espín, L., \& Gálvez Muñoz, L. (2019). A well-being of their own: Children's perspectives of well-being from the capabilities approach. Childhood, 26(1), 22-38. https://doi.org/10.1177/0907568218804872

Donders, A. R. T., Van Der Heijden, G. J., Stijnen, T., \& Moons, K. G. (2006). A gentle introduction to imputation of missing values. Journal of Clinical Epidemiology, 59(10), 1087-1091. https:// doi.org/10.1016/j.jclinepi.2006.01.014

Durham, D. (2008). Apathy and agency: The romance of agency and youth in Botswana. Figuring the Future: Globalization and the temporalities of children and youth, 151-178.

Dyregrov, A., Yule, W., \& Olff, M. (2018). Children and natural disasters. European Journal of Psychotraumatology, 9(2). https:// doi.org/10.1080/20008198.2018.1500823

Edmonds, R. (2019). Making children's 'agency' visible: Towards the localization of a concept in theory and practice. Global Studies of Childhood, 9(3), 200-211. https://doi.org/10.1177/20436 10619860994

Elder, G. H., Johnson, M. K., \& Crosnoe, R. (2003). The emergence and development of life course theory. In Handbook of the life course (pp. 3-19). Springer. https://doi.org/10.1007/ 978-0-306-48247-2_1.

Eteläpelto, A., Vähäsantanen, K., Hökkä, P., \& Paloniemi, S. (2013). What is agency? Conceptualizing professional agency at work. Educational Research Review, 10, 45-65. https://doi.org/10. 1016/j.edurev.2013.05.001

Field, A. (2009). Discovering statistics using SPSS. Third Edition. https://doi.org/10.1111/j.1365-2648.2007.04270_1.x

Gagne, P., \& Hancock, G. R. (2006). Measurement model quality, sample size, and solution propriety in confirmatory factor models. Multivariate Behavioral Research, 41, 65-83. https://doi.org/10. 1207/s15327906mbr4101_5

Habashi, J. (2011). Children's agency and Islam: Unexpected paths to solidarity. Children's Geographies, 9(2), 129-144. https://doi. org/10.1080/14733285.2011.562377
Habashi, J., \& Worley, J. (2009). Child geopolitical agency: A mixedmethods case study. Journal of Mixed Methods Research, 3(1), 42-64. https://doi.org/10.1177/1558689808326120

Hair, J., Black, B., Babin, B., Anderson, R., \& Tatham, R. (2006). Multivariate data analysis (6th ed.). Prentice-Hall. https://doi. org/10.2307/2348783

Handel, A. (2009). Where, where to and when in the occupied territories: An introduction to geography of disaster. In A. Ophir, M. Givoni, \& S. Hanafi (Eds.), The power of inclusive exclusion: Anatomy of the Israeli rule in the occupied territories (pp.179222). Zone Books.

Hart, C. S., \& Brando, N. (2018). A capability approach to children's well-being, agency, and participatory rights in education. European Journal of Education, 53(3), 293-309. https://doi.org/10. 1111/ejed.12284

Hattie, J. A. (1985). Methodology review: Assessing unidimensionality of tests and items. Applied Psychological Measurement, 9, 139-164. https://doi.org/10.1177/014662168500900204

Hitlin, S., \& Elder Jr., G. H. (2007). Time, self, and the curiously abstract concept of agency. Sociological Theory, 25(2), 170-191. https://doi.org/10.1111/j.1467-9558.2007.00303.x

Hitlin, S., \& Long, C. (2009). Agency as a sociological variable: A preliminary model of individuals, situations, and the life course. Sociology Compass, 3(1), 137-160. https://doi.org/10.1111/j. 1751-9020.2008.00189.x

Holgado-Tello, F. P., Chacón-Moscoso, S., Barbero-García, I., \& Vila-Abad, E. (2010). Polychoric versus Pearson correlations in exploratory and confirmatory factor analysis of ordinal variables. Quality \& Quantity, 44(1), 153-166. https://doi.org/10. 1007/s11135-008-9190-y

Horn, J. L. (1965). A rationale and test for the number of factors in factor analysis. Psychometrika, 30(2), 179-185. https://doi.org/ 10.1007/bf02289447

Human Rights Watch (HRW). (2019). Israel and Palestine, world report 2019. Scribbrs. Retrieved from internet on November, 8 at https://www.hrw.org/world-report/2019/country-chapters/ israel/palestine\#

Hydén, M. (2014). The teller-focused interview: Interviewing as a relational practice. Qualitative Social Work, 13(6), 795-812. https:// doi.org/10.1177/1473325013506247

Ibrahim, S., \& Alkire, S. (2007). Agency and empowerment: A proposal for internationally comparable indicators. Oxford Development Studies, 35(4), 379-403. https://doi.org/10.1080/13600 810701701897

Kaiser, H. F. (1960). The application of electronic computers to factor analysis. Educational and Psychological Measurement, 20(1), 141-151. https://doi.org/10.1177/0013164460 02000116

Kline, R. B. (2010). Principles and practice of structural equation modeling (3rd ed.). Guilford Press. https://doi.org/10.1177/10497 31509336986

Klocker, N. (2007). An example of 'thin' agency: Child domestic workers in Tanzania. https://doi.org/10.4324/9780203942222-16.

Kovner, B., \& Shalhoub-Kevorkian, N. (2018). Children, human rights organizations, and the law under occupation: The case of Palestinian children in East Jerusalem. The International Journal of Human Rights, 22(5), 616-639. https://doi.org/10.1080/13642 987.2017.1397635

Lautamo, T., Paltamaa, J., Moilanen, J., \& Malinen, K. (2021). Psychometric properties of the Assessment Tool for Perceived Agency (ATPA-22)-utility for the rehabilitation of young adults not in education, employment or training (NEETs). Scandinavian Journal of Occupational Therapy, 28(2), 97-109. https://doi.org/10. 1080/11038128.2020.1782983

Lewis, T. F. (2017). Evidence regarding the internal structure: Confirmatory factor analysis. Measurement and Evaluation in Counseling 
and Development, 50(4), 239-247. https://doi.org/10.1080/07481 756.2017.1336929

Lieten, G. K. (2008). Children, structure, and agency: Realities across the developing world. Routledge. https://doi.org/10. 4324/9780203895269

Lohr, S. L., \& Rao, J. N. K. (2000). Inference from dual frame surveys. Journal of the American Statistical Association, 95(449), 271-280. https://doi.org/10.1080/01621459.2000.10473920

Lorenzo-Seva, U., \& Ferrando, P. J. (2015). POLYMAT-C: A comprehensive SPSS program for computing the polychoric correlation matrix. Behavior Research Methods, 47(3), 884-889. https://doi.org/10.3758/s13428-014-0511-x

Mahamid, F. A. (2020). Collective trauma, quality of life and resilience in narratives of third-generation Palestinian refugee children. Child Indicators Research, 13, 2181-2204. https://doi. org/10.1007/s12187-020-09739-3

Mahamid, F., \& Berte, D. Z. (2020). Happiness, sadness, and hope for the future in narratives of Palestinian refugee children. International Journal of Mental Health and Addiction, 18(6), 1638-1651. https://doi.org/10.1007/ s11469-020-00303-2

Mahamid, F., \& Veronese, G. (2020). Psychosocial interventions for third-generation Palestinian refugee children: Current challenges and hope for the future. International Journal of Mental Health and Addiction, 1-18. https://doi.org/10.1007/ s11469-020-00300-5.

Marshall, D. J. (2013). 'All the beautiful things': Trauma, aesthetics and the politics of Palestinian childhood. Space and Polity, 17(1), 53-73. https://doi.org/10.1080/13562576.2013.780713

Marshall, D. J. (2014). Save (us from) the children: Trauma, Palestinian childhood, and the production of governable subjects. Children's Geographies, 12(3), 281-296. https://doi.org/10. 1080/14733285.2014.922678

Massad, S., Stryker, R., Mansour, S., \& Khammash, U. (2018). Rethinking resilience for children and youth in conflict zones: The case of Palestine. Research in Human Development, 15(34), 280-293. https://doi.org/10.1080/15427609.2018.1502548

Matsunaga, M. (2010). How to factor-analyze your data right: Do's, Don'ts, and How-To's. International Journal of Psychological Research, 3(1), 97-110. https://doi.org/10.21500/20112084. 854.

Mertler, C. A., \& Reinhart, R. V. (2016). Advanced and multivariate statistical methods: Practical application and interpretation. Taylor \& Francis. https://doi.org/10.4324/9781315266978

Milfont, T. L., \& Fischer, R. (2010). Testing measurement invariance across groups: Applications in crosscultural research. International Journal of Psychological Research, 3(1), 111-130. https:// doi.org/10.21500/20112084.857.

Morin, A. J. S., Marsh, H. W., \& Nagengast, B. (2013). Exploratory structural equation modeling. In Hancock, G. R. \& Mueller, R. O. (Eds.), Structural equation modeling: A second course (2nd ed., pp. 395-436). Information Age Publishing.

Noom, M. (1999). Adolescent autonomy: Characteristics and correlates. Eburon Publishers.

O'Connor, B. P. (2000). SPSS and SAS programs for determining the number of components using parallel analysis and Velicer's MAP test. Behavior Research Methods, Instruments, \& Computers, 32(3), 396-402. https://doi.org/10.3758/bf03200807

Organization for Economic Co-operation and Development (OECD). (2020). COVID-19 crisis response in MENA countries. Scribbr. Retrieved from internet on November, 8 at https://www.oecd. org/coronavirus/policy-responses/covid-19-crisis-response-inmena-countries/.

Oswell, D. (2013). The agency of children: From family to global human rights. Cambridge University Press. https://doi.org/10. 1017/cbo9781139033312.002
Palestinian Center Bureau of Statistics (PCBs). (2016). Estimated Population in the Palestinian Territories Mid-Year by Governorate, 1997-2016. Available from: http://www.pcbs.gov.ps/Portals/_ Rainbow/Documents/gover.htm.

Payne, R. (2012). 'Extraordinary survivors' or 'ordinary lives'? Embracing 'everyday agency' in social interventions with childheaded households in Zambia. Children's Geographies, 10(4), 399-411. https://doi.org/10.1080/14733285.2012.726071

Pearlin, L. I., \& Schooler, C. (1978). The structure of coping. Journal of Health and Social Behavior, 2-21. https://doi.org/10. 2307/2136319

Pedaste, M., \& Leijen, Ä. (2020). Decision making through the angle of the ecological model of agency. In 2020 IEEE 20th International Conference on Advanced Learning Technologies (ICALT) (pp. 243-245). IEEE. https://doi.org/10.1109/ icalt49669.2020.00080.

Pinkard, N. (2019). Freedom of movement: Defining, researching, and designing the components of a healthy learning ecosystem. Human Development, 62(1-2), 40-65. https://doi.org/10.1159/ 000496075

Pituch, K. A., \& Stevens, J. P. (2015). Applied multivariate statistics for the social sciences: Analyses with SAS and IBM's SPSS. Routledge. https://doi.org/10.4324/9781315814919

Poteat, V. P., Calzo, J. P., \& Yoshikawa, H. (2018). Gay-straight Alliance involvement and youths' participation in civic engagement, advocacy, and awareness-raising. Journal of Applied Developmental Psychology, 56, 13-20. https://doi.org/10. 1016/j.appdev.2018.01.001

Prout, A., \& James, A. (1990). Constructing and reconstructing childhood: New directions in the sociological study of childhood. Routledge. https://doi.org/10.4324/9781315745008

Qouta, S., Punamäki, R. L., \& El Sarraj, E. (2008). Child development and family mental health in war and military violence: The Palestinian experience. International Journal of Behavioral Development, 32(4), 310-321. https://doi.org/10.1177/ 0165025408090973

Qvortrup, J. (2005). Varieties of childhood. In Studies in modern childhood (pp. 1-20). Palgrave Macmillan, . https://doi.org/10. 1057/9780230504929_1.

Reeve, J., \& Tseng, C. M. (2011). Agency as a fourth aspect of students' engagement during learning activities. Contemporary Educational Psychology, 36(4), 257-267. https://doi.org/10. 1016/j.cedpsych.2011.05.002

Richardson, R., Schmitz, N., Harper, S., \& Nandi, A. (2019). Development of a tool to measure women's agency in India. Journal of Human Development and Capabilities, 20(1), 26-53. https:// doi.org/10.1080/19452829.2018.1545751

Schumacher, R. E. (2005). Introduction to structural equation modeling: Reading 4, developing structure equation models. Institute for Statistics Education.

Settersten, R. A., \& Gannon, L. (2005). Structure, agency, and the space between: On the challenges and contradictions of a blended view of the life course. Advances in Life Course Research, 10(05), 35-55. https://doi.org/10.1016/s10402608(05)10001-x

Sinclair, M. (2001). Education in emergencies. Learning for a future: Refugee education in developing countries. Commonwealth Education Partnerships. Commonwealth Secretariat, 52-56.

Snyder, C. R., Sympson, S. C., Ybasco, F. C., Borders, T. F., Babyak, M. A., \& Higgins, R. L. (1996). Development and validation of the State Hope Scale. Journal of Personality and Social Psychology, 70(2), 321. https://doi.org/10.1037/0022-3514.70.2.321

Snyder, C. R., Hoza, B., Pelham, W. E., Rapoff, M., Ware, L., Danovsky, M., \& Stahl, K. J. (1997). The development and validation of the Children's Hope Scale. Journal of Pediatric Psychology, 22(3), 399-421. https://doi.org/10.1093/jpepsy/22.3.399 
Sousa, C. A., Kemp, S. P., \& El-Zuhairi, M. (2019). Place as a social determinant of health: Narratives of trauma and homeland among Palestinian women. The British Journal of Social Work, 49(4), 963-982. https://doi.org/10.1093/bjsw/bcz049

Spyrou, S. (2018). Disclosing childhoods. In Disclosing childhoods (pp. 1-14). Palgrave Macmillan, . https://doi.org/10.1057/ 978-1-137-47904-4_1.

Steckermeier, L. C. (2019). Better safe than sorry. Does agency moderate the relevance of safety perceptions for the subjective wellbeing of young children? Child Indicators Research, 12(1), 29-48. https://doi.org/10.1007/s12187-017-9519-y

Strang, A., \& Wessells, M. G. (Eds.). (2006). A world turned upside down: Social ecological approaches to children in war zones. Kumarian Press. doi: https://doi.org/10.1097/wtf.0b013e3283 07eeea.

Taber, S. M. (2010). The veridicality of children's reports of parenting: A review of factors contributing to parent-child discrepancies. Clinical Psychology Review, 30, 999-1010. https://doi.org/10. $1177 / 1073191119832655$

Teddlie, C., \& Yu, F. (2007). Mixed methods sampling: A typology with examples. Journal of Mixed Methods Research, 1, 77-100. https://doi.org/10.1177/1558689806292430

Valentine, K. (2011). Accounting for agency. Children \& Society, 25(5), 347-358. https://doi.org/10.1111/j.1099-0860.2009. 00279.x

Velicer, W. F., Eaton, C. A., \& Fava, J. L. (2000). Construct explication through factor or component analysis: A review and evaluation of alternative procedures for determining the number of factors or components. In R. D. Goffin \& E. Helmes (Eds.), Problems, and solutions in human assessment: Honoring Douglas N. Jackson at seventy (pp. 41-71). Kluwer Academic. https://doi.org/10.1007/ 978-1-4615-4397-8_3.

Veronese, G., \& Cavazzoni, F. (2020). "I hope I will be able to go back to my home city": Narratives of suffering and survival of children in Palestine. Psychological Studies, 65(1), 51-63. https://doi.org/ 10.1007/s12646-019-00502-5

Veronese, G., \& Pepe, A. (2021). Measuring traumatic reactions in Palestinian children: A psychometric assessment of the children revised impact of event scale-Arabic version (CRIES-13A). Child Psychiatry \& Human Development, 1-11. doi: https://doi. org/10.1007/s10578-020-01113-2.

Veronese, G., Pepe, A., Jaradah, A., Murannak, F., \& Hamdouna, H. (2015). Quality of life and determinants of parents' school satisfaction in war contexts: A mixed-method exploratory study in Palestine. SAGE Open, 5(4). https://doi.org/10.1177/2158244015 608422

Veronese, G., Pepe, A., \& Afana, A. (2016). Conceptualizing the wellbeing of helper operating in war-like condition: A mixed-method approach. International Social Work, 59, 938-952. https://doi. org/10.1177/0020872814537855

Veronese, G., Pepe, A., Dagdouke, J., Addimando, L., \& Yagi, S. (2017a). Measuring well-being in Israel and Palestine: The subjective well-being assessment scale. Psychological Reports, 120(6), 1160-1177. https://doi.org/10.1177/0033294117715479

Veronese, G., Pepe, A., Jaradah, A., Murannak, F., \& Hamdouna, H. (2017b). "we must cooperate with one another against the enemy": Agency and activism in school-aged children as protective factors against ongoing war trauma and political violence in the Gaza strip. Child Abuse \& Neglect, 70, 364-376. https://doi. org/10.1016/j.chiabu.2017.06.027

Veronese, G., Cavazzoni, F., \& Antenucci, S. (2018). Narrating hope and resistance: A critical analysis of sources of agency among Palestinian children living under military violence. Child: Care, Health, and Development, 44(6), 863-870. https://doi.org/10. 1111/cch.12608

Veronese, G., Pepe, A., Cavazzoni, F., Obaid, H., \& Perez, J. (2019). Agency via life satisfaction as a protective factor from cumulative trauma and emotional distress among Bedouin children in Palestine. Frontiers in Psychology, 10, 1674. https://doi.org/10. 3389/fpsyg.2019.01674

Veronese, G., Pepe, A., Obaid, H., Cavazzoni, F., \& Perez, J. (2020a). Agency and life satisfaction in Bedouin children exposed to conditions of chronic stress and military violence: A two-wave longitudinal study in Palestine. Clinical Child Psychology and Psychiatry, 25(1), 242-259. https://doi.org/10.1177/1359104519 864134

Veronese, G., Sousa, C., Cavazzoni, F., \& Shoman, H. (2020b). Spatial agency as a source of resistance and resilience among Palestinian children living in Dheisheh refugee camp, Palestine. Health \& Place, 62, 102304. https://doi.org/10.1016/j.healthplace.2020. 102304

Watkins, M. (2008). Monte Carlo PCA for parallel analysis 2.3. Ed \& Psych Associates.

Weller, S. C., \& Romney, A. K. (1988). Systematic data collection (Vol. 10). Sage publications. https://doi.org/10.4135/9781412986069.

Wilson, N., Turner-Halliday, F., \& Minnis, H. (2021). Escaping the inescapable: Risk of mental health disorder, somatic symptoms, and resilience in Palestinian refugee children. Transcultural Psychiatry, 58(2), 307-320. https://doi.org/10.1177/1363461520 987070

World Health Organization (WHO). (2021). Occupied Palestinian territory. Coronavirus disease 2019 (COVID-19) situation report 76. Scribbr. https://who18.createsend.com/campaigns/repor ts/viewCampaign.aspx? $\mathrm{d}=\mathrm{j} \& \mathrm{c}=99 \mathrm{FA} 4938 \mathrm{D} 049 \mathrm{E} 3 \mathrm{~A} 8 \& \mathrm{ID}=$ 6A459D066B73581E2540EF23F30FEDED\&temp=False \& tx $=$ 0\&source $=$ Report

World Medical Association. (2013). WMA declaration of Helsinki. Ethical principles for medical research involving human subjects.

Yount, K. M., Khan, Z., Miedema, S., Cheong, Y. F., \& Naved, R. T. (2020). The Women's Agency Scale 61 (Was-61): A comprehensive measure of women's intrinsic, instrumental, and collective agency. Instrumental, and Collective Agency (August 9, 2020). https://doi.org/10.2139/ssrn.3670180.

Zimmerman, L. A., Li, M., Moreau, C., Wilopo, S., \& Blum, R. (2019). Measuring agency as a dimension of empowerment among young adolescents globally; findings from the global early adolescent study. SSM-population health, 8. https://doi.org/10.1016/j.ssmph. 2019.100454

Publisher's Note Springer Nature remains neutral with regard to jurisdictional claims in published maps and institutional affiliations. 